\title{
Climate Change Adaptation and Mitigation Strategies for Small Holder Farmers: A Case of Nyanga District in Zimbabwe
}

\author{
Terence Darlington Mushore ${ }^{1,2 \star}$, Teddious Mhizha ${ }^{1}$, Moven Manjowe ${ }^{1}$, Linia Mashawi ${ }^{3}$, \\ Electdom Matandirotya ${ }^{1}$, Emmanuel Mashonjowa ${ }^{1}$, Collen Mutasa ${ }^{1}$, Juliet Gwenzi ${ }^{1}$ and \\ George Tawanda Mushambi ${ }^{4}$ \\ ${ }^{1}$ Department of Space Science and Applied Physics, University of Zimbabwe, Harare, Zimbabwe, ${ }^{2}$ Discipline of Geography, \\ School of Agricultural, Earth and Environmental Sciences, University of KwaZulu-Natal, Pietermaritzburg, South Africa, \\ ${ }^{3}$ Meteorological Services Department of Zimbabwe, Corner Bishop Gaul/Hudson, Harare, Zimbabwe, ${ }^{4}$ Geography \\ Department, Bindura University of Science Education, Bindura, Zimbabwe
}

OPEN ACCESS

Edited by:

Delia Catacutan,

World Agroforestry Centre, Indonesia

Reviewed by:

Donghoon Lee,

University of California, Santa Barbara,

United States

Danang Eko Nuryanto,

Indonesian Agency for Meteorology,

Climatology and

Geophysics, Indonesia

*Correspondence:

Terence Darlington Mushore tdmushore@science.uz.ac.zw;

mushoret@ukzn.ac.za

Specialty section:

This article was submitted to

Climate Services,

a section of the journa

Frontiers in Climate

Received: 05 March 2021

Accepted: 06 July 2021

Published: 06 August 2021

Citation:

Mushore TD, Mhizha T, Manjowe M,

Mashawi L, Matandirotya E,

Mashonjowa E, Mutasa C, Gwenzi J

and Mushambi GT (2021) Climate

Change Adaptation and Mitigation

Strategies for Small Holder Farmers: A

Case of Nyanga District in Zimbabwe.

Front. Clim. 3:676495.

doi: 10.3389/fclim.2021.676495
Climate change encompassing mostly hydro-meteorological hazards is a reality affecting the world in diverse ways. It is manifesting in various ways such as increases in frequency and intensity of floods, droughts, and extreme temperatures. In recent years, climate change has induced droughts, other extreme weather events and meteorological disasters in many countries including Zimbabwe. Effective management of climate change induced challenges require localized strategies which may vary from one part of the world to another and even within a country. In view of the need to understand localized impacts and responses to climate change, the main objectives of the study were to (i) assess the impact of climate change on livelihoods and food security, (ii) identify and evaluate adaptation and mitigation strategies that small holder farmers in Ward 17, Nyanga, Zimbabwe have developed. The research used both qualitative and quantitative approaches with data collection methods comprising of questionnaires (56), observations and interviews (8). The tools were used to gather information which included encounters with extreme weather events, climatic trends as well as adaptive responses. The findings showed that climate change had a significant negative impact on the livelihoods and food security status of small holder farmers in ward 17 of Nyanga district. The identified climate change adaptation strategies implemented in the study area included food aid, use of traditional grains and other drought resistant crops, early planting, multiple planting, barter trade and livelihood diversification. The mitigation strategies used included afforestation and reforestation programs, avoiding veld fires and preservation of wetlands. The research identified challenges to climate change adaptation which include lack of markets to sell farming produce, inefficient institutions, poverty and high climate variability and increased uncertainty in the behavior of seasons. The findings of this study indicated the need for similar assessment in other parts of the country as impacts of climate change and responses thereof should vary from place to place.

Keywords: climate change, Nyanga district, rainfall, agriculture, mitigation, Zimbabwe 


\section{INTRODUCTION}

Global warming during the 20th Century in Africa has been estimated at between 0.26 and $0.5^{\circ} \mathrm{C}$ per decade (IPCC, 2007). This trend is expected to continue and even to increase significantly, with a consequent impact on livelihoods. According to the Intergovernmental Panel on Climate Change (IPCC, 2007), a medium-high emission scenario would see an increase in annual mean surface air temperatures of between 3 and $4{ }^{\circ} \mathrm{C}$ by 2080 . This implies difficult times ahead for local people that depend directly/indirectly on agriculture especially rain fed agriculture for their livelihoods and have few assets or strategies to cope with the changes to come. Other observed effects of climate change include reduced reliability of rainfall, increased frequency of extreme events such as prolonged dry spells, droughts and floods as well as poor intra-season spatial and temporal distribution of seasonal rainfall. In Zimbabwe, recorded temperatures have risen by about $1^{\circ} \mathrm{C}$ over the last 40 years of the twentieth century, while rainfall and runoff decreased by $\sim 20$ and 30 percent, respectively (Watson et al., 1998). The frequency of droughts has also increased from once per decade to about once every 3 years in Zimbabwe (FAO, 2004). Unganai (2009) points out that rainfall exhibits considerable spatial and temporal variability characterized by shifts in the onset of rains and increases in the frequency and intensity of heavy rainfall activity. This significantly compromise crop production especially for small holder farmers who depend heavily on agriculture and lack in irrigation and water harvesting technologies. Small holder farmers, whose livelihood depends on the use of natural resources and rain fed agriculture, are likely to suffer most the brunt and adverse effects of climate change (IPCC, 2001b). With rain fed agriculture failing, the situation is worsened by lack of other sources of any income needed to buy food supplements in the area of study (Deressa and Rashid, 2010). Hence drought and climate change often turn into disasters since the copying mechanisms in the region are limited in capacity (Gwimbi, 2009).

According to the Zimbabwe Draft Response to Climate Change (2013), the government of Zimbabwe regards climate change as a potential threat which undermines positive development made so far in the country in meeting the developmental goals like the millennium development goal number one which was aimed at eradicating extreme hunger and poverty. Zimbabwe has demonstrated its willingness to contribute to the preservation of the global climate for sustainable development through the formulation of the Zimbabwe National Environmental Policy and Strategies which broadly covers issues to do with climate change. However, Chagutah (2010) noted that capacity in African counties is limited by high levels of poverty and underdevelopment and Zimbabwe is not an exception. The study on the impact of climate change on the local populations' livelihoods is increasingly forwarded as an urgent research need. Bunce et al. (2010) noted that the African continent is increasingly becoming a major global food crisis spot if there are no efforts to address climate change at the local level. As Nath and and Behera (2011) argue that local assessment of vulnerability enables a better understanding of how and why communities respond to the same type of environmental stress in ways that are different. As such the impact of climate change across the globe also differs. With this in mind, it becomes imperative as Nath and and Behera (2011) notes, to understand the actual dynamics of climate change impact and responses at the lowest levels of the society, such as households, communities and districts so as to influence responsive relief interventions.

Climate change adaptation and mitigation strategies vary from place to place even within the same country. Understanding of strategies employed in an area is important for modification and adoption of strategies in other areas. Studies which look at area specific responses are important for creating a national and global database for climate change adaptation and mitigation strategies. In light of this, while other studies have looked at strategies such as in Bikita (Mushore et al., 2013) and recently in Chipinge (Mavhura et al., 2017) it is also important to understand how climate change is being tackled in other areas such as Nyanga District in the eastern parts of Zimbabwe. To the best of our knowledge, no emphasis has been placed on these climatic transformations which are threatening the sustainability of subsistence or smallholder agriculture in Nyanga. Nyanga is located in the semi-arid climatic regions hence understanding adaptation and mitigation strategies in such a dry area would benefit wetter areas as they adjust to projected decline in rainfall. The objectives of this study are thus to (i) assess the impact of climate change on livelihoods and food security, (ii) identify climate change adaptation and mitigation strategies employed in Ward 17 of Nyanga District in Zimbabwe, and (iii) highlight the ward level challenges to climate change adaptation and mitigation strategies.

\section{METHODOLOGY}

\section{Description of the Study Area}

Nyanga district is located in Manicaland province in the Eastern Highlands of Zimbabwe (Figure 1). The district consists of 31 wards. Ward 17 of the district consists of 12 villages. The target population comprises of communal farmers in Ward 17 of Nyanga District. ZIMSTAT (2012), indicated that Nyanga Rural District has a population of 126577 . Ward 17, which is under study has a total population of 10,605 of which 4,040 are males and 6,555 females. The Ward has a total of 1,370 households. The larger part of the district is located in Natural Farming Region 1, but Ward 17 is located in natural Natural Farming Region 4, which is characterized by low and erratic rainfall. The type of vegetation is characterized by thorn bushes, baobab trees and acacia, implying that the area generally receives low rainfall. There are prominent agricultural practices which are primarily subsistence farming.

\section{Target Population}

One thousand three hundred and seventy $(1,370)$ households were too large to work with due to shortage of time and financial resources. Saunders et al. (2003) suggested that a sample size can be defined by using $10-20 \%$ of the targeted population. A total of 56 subsistence farmers was selected using simple random sample and purposive sampling technique. This sample was large 


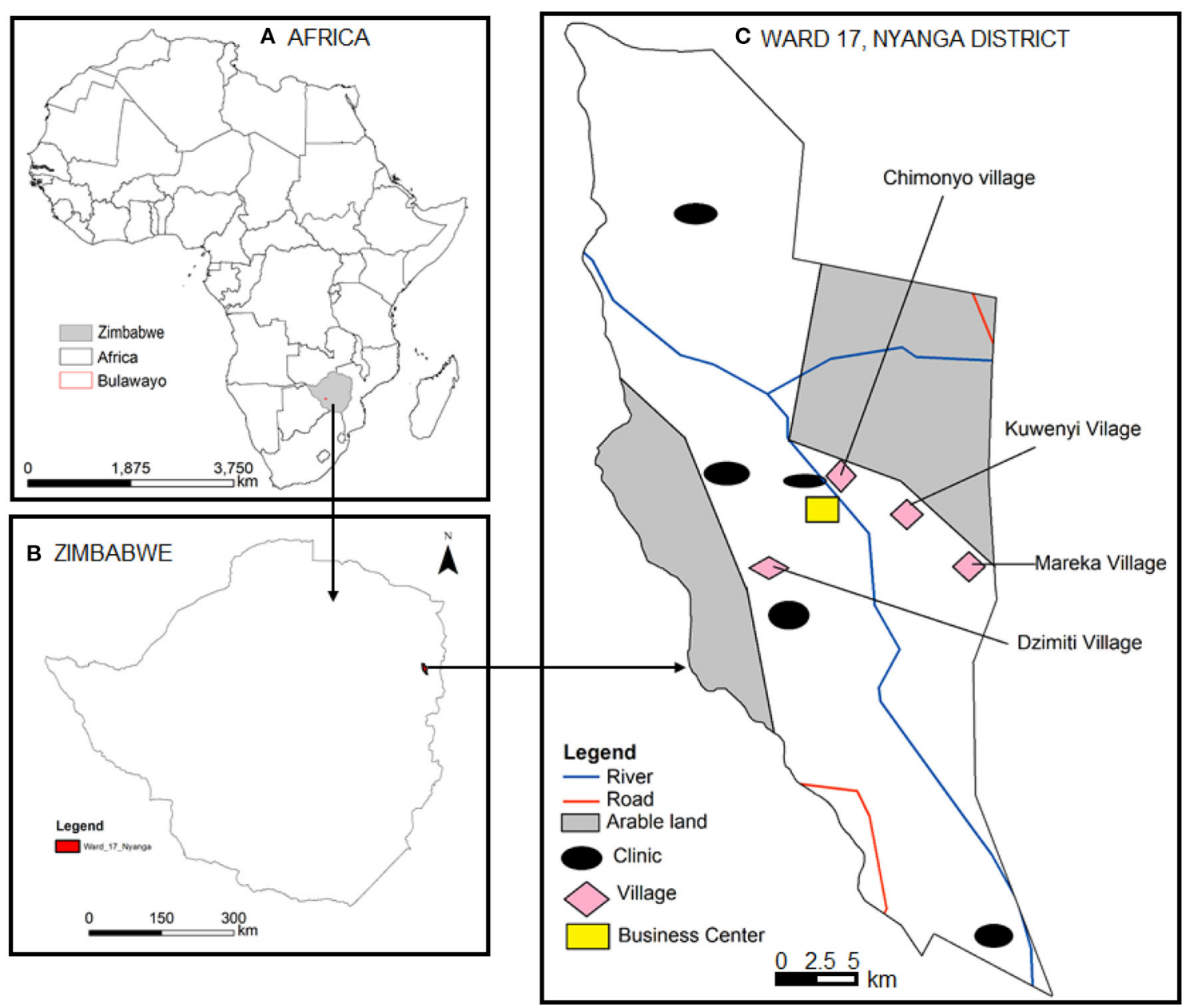

FIGURE 1 | Location of Zimbabwe in Africa (A), study area in Zimbabwe (B), and map of Ward 17 of Nyanga District (C).

enough to make some generalizations about the ward since the respondents were selected from different spaced households.

\section{Research Instruments}

For a comprehensive evaluation of the effectiveness of strategies in mitigation and adaptation to climate change programs in food insecurity reduction, multiple data collection techniques were needed. The data collection instruments used include questionnaires, interviews and observations. The usage of multiple data collection tools was meant to ensure that the weakness of one tool would be covered by another. During field surveys, observations were made to identify information on poverty levels, evidence of adaptation and mitigation as well as livelihood strategies.

The questionnaires were designed to solicit information from the general villagers. The questionnaire focused on issues such as: adaption and mitigation, types of crops grown, food intakes per day, type of livestock and other assets or resources owned by the farmers and involved in helping the farmers. The challenges being faced in implementing new farming methods were also of interest.

Structured interview guides were designed to solicit the same information from key informant members of the community. The purpose of key informant interviews was to collect information from a wide range of people including community leaders, professionals, or residents especially the elderly who had historical glimpse of weather and climate change and have firsthand knowledge about the community. Observation guides were also designed to help the researcher to obtain information based on related indicators that would be seen while moving around the area. This was used by the researcher to identify some of the issues that may not be aired out clearly during interviews and questionnaires.

The usability of the instruments was tested before use for actual data collection, known as pre-testing. Questionnaire was tested at a random office at Environment Management Agency while interview guides were administered in the ward before the actual data collection. This helped to check the reliability and validity of these instruments as well as to ensure that the 
TABLE 1 | Distribution of respondents.

\begin{tabular}{lccc}
\hline \multirow{2}{*}{ Targeted respondents } & \multicolumn{2}{c}{ Number of respondents } & \multirow{2}{*}{ Response rate (\%) } \\
\cline { 2 - 3 } & Targeted & Actual & \\
\hline Village heads (interviews) & 3 & 3 & $100 \%$ \\
Villagers (questionnaires) & 56 & 50 & $89 \%$ \\
EMA (interviews) & 1 & 1 & $100 \%$ \\
AGRITEX officers (interviews) & 2 & 2 & $100 \%$ \\
NGOs (interviews) & 2 & 2 & $100 \%$ \\
\hline Total & 64 & 58 & $90 \%$ \\
\hline
\end{tabular}

tools were clear enough to gather data covering all the objectives. Correction and rephrasing of issues which were confusing to the respondents were done.

\section{Data Collection Procedures}

The researcher acquired approval from the Ward 17 Councilor and village heads before embarking on the study after vividly explaining the objectives and aim of the study to community leaders. After clearing issues which have something to do with permission and approval the researcher went on to the participants of the farmer's questionnaire. The researcher also made appointments with key informants from, Environment Management Agency (EMA), Agricultural and Technical Extension (AGRITEX) officers, non-governmental organizations which offer climate related technical assistance to farmers and ward 17 village heads. Key informants were composed of one individual from EMA, two from AGRITEX, three village heads and two from Non-Governmental Organizations (NGOs). The selection of these key informants is based on their proximity to Ward 17 and also the in depth knowledge on the problem under study. After the appointments had been done the researcher conducted face to face interviews with above mentioned key informants (Table 1). Before the interview meeting with the key informants, the researcher practiced and familiarized with the script and questions to ensure there were no biases and confusion during the interview. The researcher also observed the types of crops which were under cultivation to evaluate if the varieties are resilient to climate change and variability.

Three key informants consisting of one from the Ministry of Environment and Climate Change specifically from EMA and two from Agriculture Extension (AGRITEX) Office were targeted and reached and the other two were targeted from NGOs which are doing a DRR/disaster risk reduction program in the ward. Both were reached through interviews to provide information on climate change and its effects on food security and livelihoods in the area of study (Table 1). They also elaborated the work being done by government through the role they are playing in reducing the effects of climate change. The AGRITEX officers provided information on the implementation of adaptation and coping mechanisms as well as accounts of vulnerabilities of people on the ground to the effects of climate change.

\section{Reliability and Validity}

Reliability and validity were ensured through the use of multiple instruments referred to as triangulation and in this study questionnaire, interviews and observations were utilized. Validity was catered for by cross checking for consistency. Triangulation is a powerful technique that facilitates validation of data through cross verification from more than two instruments (Kimchi et al., 1991). In this study information from questionnaires, interviews and observations were validated by inter-comparison. Similar data from these different sources were compared to check for consistence and collect as much information from all the methods used as possible. Errors and suspicious data from any of the methods were identified and corrected using information from the other complementary sources.

\section{Data Analysis Procedure}

The collected data were analyzed using Microsoft Excel as well as Statistical Package for Social Scientists (SPSS) where simple descriptive statistics were obtained and results were summarized as graphs and pie charts for discussions. Quantitative data from the questionnaires were analyzed using Statistical Package for Social Science (SPSS), Microsoft excel and were analyzed thematically. Transcripts from interviews were analyzed using the participant's own words and without preconceived classification. The participant's language and phrases were examined; categorized and recurrent themes were identified. Recurrent themes are the similar and consistent ways people think about, and give accounts on concerning particular issues. For open ended questionnaires, the researcher looked into the themes as they emerged from the data as they were coded and then put into conceptual categories and the results were described.

Responses collected using the different instruments mentioned above were sorted into classes namely climate change adaptation strategies, mitigation strategies, impact of climate change to livelihoods, challenges to climate change mitigation and adaptation and impact of drought mitigation strategies.

The first analysis involved identification and assessment of the effectiveness of climate change adaptation strategies. The percentages of the participants who view each of the technique as effective or otherwise were recorded. The second analysis involved identification of climate change mitigation strategies in use and counting of the number of people who pointed out each of the strategies in Ward 17 of the Nyanga District. Another analysis was done which identified challenges faced in adaptation and mitigation of climate change in Ward 17 of the Nyanga District and counting the number of people who pointed out each as a challenge.

\section{PRESENTATION AND DISCUSSION OF RESEARCH FINDINGS}

Climate change is affecting a variety of socio-economic activities in Zimbabwe including Ward 17 of Nyanga District. The evidence include rising temperature, increased frequency of floods, dry spells, droughts and other extreme events (Releifweb, 
2011; Brazier, 2015). While the economy of Zimbabwe strongly relies on agriculture which is largely rain-fed, hydrometerological extremes are compromising productivity. For instance, the start and end of season have increasingly become uncertain making it difficult to decide on setting planting dates and selecting crop varieties to grow (Mushore et al., 2017). Even in a season where rainfall totals are within or exceed long term average, quality of the season is causing decline in productivity such as through prolonged and frequent mid season dry spells. The combination of declining trend in rainfall and rising temperatures has meant increase of evapo-transpiration speeding up crop growth cycles and affecting proper maturity of crops (Manatsa et al., 2017). Livestock production has also not been spared by adverse impacts of diminishing water resources and severely high temperatures not suitable for animals during some periods (Mutekwa, 2009). In view of these challenges, communities embark on a variety of efforts to survive within the changing climate (adaptation) and to reduce further changes in climate (mitigation). In the context of background changes in climate, based on information gathered using qualitative and quantitative techniques, adaptation and mitigation efforts applied in Ward 17 of Nyanga District are discussed in this section.

\section{Livelihoods Strategies Employed to Curb Climate Change Impacts in Ward 17 of Nyanga District in Zimbabwe}

As noted from Figure 2, 40\% of the respondents are into food and cash crop production, $38 \%$ are into barter and petty trade and $22 \%$ are into livelihoods diversification (Figure 2). This did not mean that some respondents are not involved in all the three livelihood strategies. The people in the area mainly rely on food and cash crop production, petty trade and barter trade and livelihoods diversification which include migration to Mozambique, selling of livestock for them to get money to supplement food requirements. This reduces their ability to productively carry out their farming activities in the coming seasons thus making them more vulnerable to food insecurity and other negative effects of climate change as they spent their time doing other off farm livelihoods activities. Sometimes they sell their livestock which reduce their draft power to meet their immediate food needs at the expense of their long time coping mechanisms. This makes some of the adaptations less effective and less sustainable. This observation confirms De Waal (1990)'s assumption that people's need to consume food drives their actions. Consequently it results in depleted draft power, which in turn limits the farmers' capacity to farm productively in the coming seasons thus making them more vulnerable to food insecurity, a phenomenon echoed by the AGRITEX officer. This therefore reverses the development made by the people confirming Davidson et al. (2003) who noted that climate change will affect the achievement of the MDGs in particular the one to do with achieving alleviating hunger and poverty.

As a result food security continues to deteriorate in the area. This was confirmed by Bunce et al. (2010) who noted that Africa has become a place for food crises. As such events

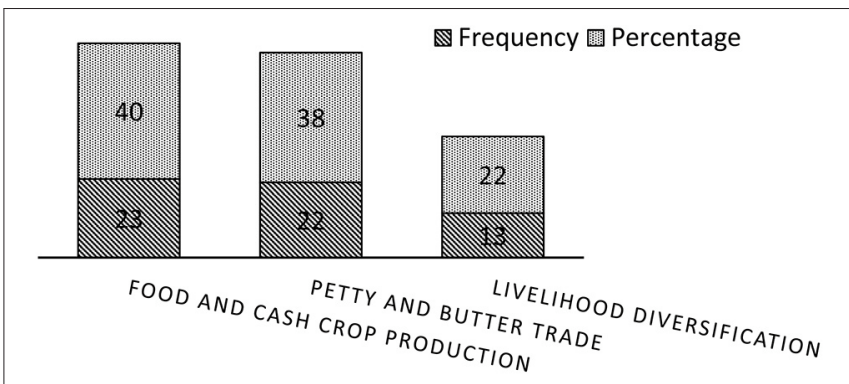

FIGURE 2 | Livelihood strategies of respondents (multiple response) $n=58$.

mainly affect the poor and the situation is exacerbated by poor governance of the available resources (Feyissa, 2007). Climate change undermines the government's capacity to cope with the rising demands for food in Africa as food production is very low particularly in Zimbabwe. Food security is really an issue in ward 17 as it is a semi-arid region and the circumstances are being worsened by the adverse effects of climate change. Most of the families in the study have at least one or two meals a day. Thus they rely mostly on handouts from NGOs. Crops like groundnuts (Arachis hypogaea) and round nuts (Vigna subterranea) are prominent there and in a way they improve on nutrition circles since they are rich in proteins.

\section{Climate Change Adaptation Strategies Used in Ward 17 of Nyanga District in Zimbabwe}

Most of the small holder farmers rely on food aid, using small grains like sorghum which are drought resistant, use of short seasoned varieties, barter trade, multiple cropping, livelihood diversification, dry planting, and early planting as climate change copying and adaptation strategies. Most of the adaptation strategies are sustainable as the smallholder farmers seem to favor them since they are less costly and are Indigenous Knowledge System/IKS based. This is usually the second response to climate change as it is hinged on finding alternative ways for instance; initiatives and policies to reduce the susceptibility of people and the environment to the harsh effects of climate change. Adaptation is usually divided into two broad categories namely ethno-science and techno-science (Matanga and Jere, 2011). Ethno-science comprise of techniques based on local people's knowledge of their physical environment while techno-science involves modern technologies. Farmers in ward 17 villages use both methods for its adaptation to climate change. However, the former are mostly used as the method is not expensive like the latter. Figure 3 shows that $25 \%$ of the respondents opted for early planting because it is less costly. This shows that the respondents indicated that they are willing to take up any kind of adaptation strategy if it proves to be less costly, thus they encouraged AGRITEX and EMA to carry out adaptation and mitigation strategies which can be at zero budget. 


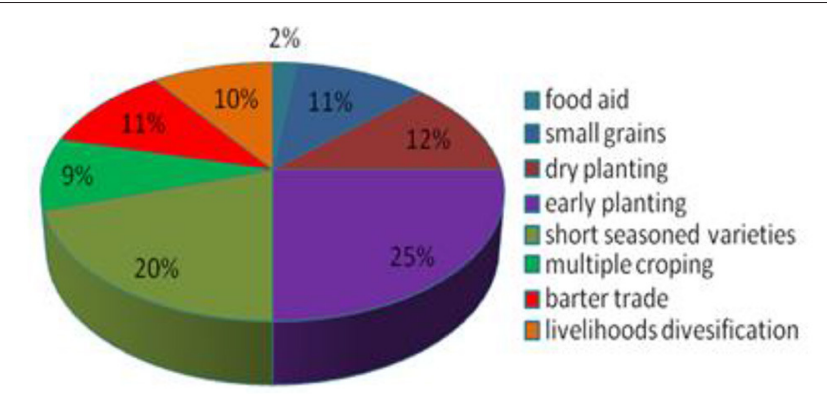

FIGURE 3 | Adaptation strategies (multiple responses) $n=58$.

\section{Ethno-Science Adaptive Measures}

Ethno-science is most commonly expressed as Indigenous Knowledge Systems (Matanga and Jere, 2011) and it usually consist of adaptation methods such as growing of drought tolerant crops, multiple planting, early planting, barter trade, planting, hiring labor, selling, and begging.

\section{Growing Drought Tolerant Crops or Small Grains}

Growing of drought tolerant small grain crops such as millet, sorghum, and rapoko is usually done to curb issues of low and unreliable rainfall (Chazovachii et al., 2010), which are caused by climate change. Current weather conditions are making it impossible to grow maize which is the staple cereal for Zimbabwe and for villagers of ward 17, since the area does not have enabling conditions for the crop to have a good yield as it is an arid area. As a result, small grain crops are suitable because they can survive in dry conditions. This is helpful because it will mostly ensure the availability of food even during drought seasons.

This is in contrast with the findings of this research as the dominant food crop being grown is maize. The majority of the subsistence farmers prefer to grow maize crops even in marginal areas like Ward 17, resulting in persistent food shortages. Although, some households now shift from maize to sorghum, there is need for awareness campaigns and education from AGRITEX on the importance of small grains in marginal areas. Also lack of access to seeds such as millet and rapoko has contributed to the ineffectiveness of this climate change adaptation strategy.

\section{Multiple Cropping to Increase Chances of Getting Yield in Harsh Climatic Conditions}

This involves planting a variety of crops such that if other crop types fail due to the given weather conditions the surviving crops would act as safety nets. Thus, they mix crops like pumpkins, maize and beans together. This helps in promoting soil fertility as the legumes are nitrogen fixing crops. Again they create soil cover which helps in soil moisture retention and preservation. Multiple cropping ensured families would get some yields to harvest even when other crops fail. In Maereka, Kuwenyi, Chimonyo, and Dzimbiti villages, they usually multi and mix crops especially groundnuts (Arachis hypogaea), round nuts (Vigna subterranea), cow peas, sugar beans, maize, sorghum, rapoko, and millet, most of which are drought tolerant.

\section{Early Planting to Take Advantage of Early Rains and Full Length of Season}

Based on the deep knowledge of their agro-ecological conditions by local people and expectation of a good rainfall season (based on indigenous indicators) crops are planted as soon as the first rains fall. CARE (2009) however, noted that some people in ward 17 village avoid this method as it can be risky since there can be some instances when the rains would go away after they had planted and that would be wastage of seeds. Some would want to practice this method but might face hindrances like lack of inputs such as seeds during the time of the first rains.

\section{Dry Planting to Counter Uncertainty in Start of Season}

Farmers prepare the land and saw their crops in September and October before the rainfall come. It is also known in the district as kupandira in the local Manyika dialect. This is done so that when the rains come the already sowed seeds will sprout with the first rains. Itis done to counter the unpredictability of rain. The types of crops which are normally dry planted include maize, ground nuts (Arachis hypogaea) and round nuts (Vigna subterranea) and rapoko. This method gives smallholder farmers a chance to focus on other off farm activities like petty trade if it is properly done. This method also helps in moisture preservation, thus making crops thrive even in dry conditions.

\section{Barter Trade in Exchange for Food Items in Times of Deficit or Poor Crop Yields}

Barter trade is also another way which people in ward 17 are using to adapt to the effects of climate change. Since they mostly grow small grain crops they usually do not have crops like maize and their households' gardens do not grow much to sustain them with vegetables, tomatoes or onions. Therefore, they have to practice barter trade within Nyanga District. One bucket of approximately $10 \mathrm{~kg}$ of millet and sorghum can be barter traded with $2 \mathrm{~kg}$ of sugar or a bar of washing soap, or vegetables, or tomatoes, or onions, or beans, or fish with people from Chimonyo village. Poultry or livestock is usually traded with maize from areas like Mutare or Mutasa. The major setback with this adaptation method is that, sometimes the villagers may be treated unfairly in terms of the standard valuation of livestock and other asserts. In some situations livestock may be exchanged for very small quantities of grains for example a heifer can be exchanged with $500 \mathrm{~kg}$ of maize.

\section{Livelihood Diversification to Sustain Lives Even When Agricultural Production Is Limited}

Casual labor, selling and begging are some of the livelihood diversification strategies which they employ. People in ward 17 especially in Chimonyo village usually go to nearby areas like Muozi and Nyanga Forests to work as casual or full time laborers so as to get money or other basic commodities they would be in need of. However, in some cases whereby drought would have hit hard, selling labor can be less practical as the areas people 
usually go to work would also be affected. This then means that the sustainability of the livelihoods is threatened. Some will be involved in activities of buying and selling clothes or household equipment and utensils that they get from urban areas or across the border, most notably from Mozambique.

Others take another unreliable source of livelihood strategy which is begging for food or money. Begging better known askutsunza or kupemha in the manyika dialect, is one of the least practiced adaptation method to climate change. This is so because rarely people will have excess supply of agricultural produce to spare. However, begging reduce one's self esteem as one has to reduce his or her pride so that the potential donors can sympathize with them and give them something. Also most vulnerable households can benefit from chieftain granary reserve as it is still being practiced by the local chief Saunyama. The findings are in tandem with the notion that there is need for the agricultural sector to diversify and start producing sorghum, millet, rapoko, sweet potatoes, cassava and yams at a large scale to meet the country's food requirements to ensure food security in Zimbabwe in the wake of climate change (Mudimu, 2003).

\section{Techno-Science Adaptive Methods}

Techno-science adaptation methods include small supplementary feeding and reliance on food aid. Africa as a continent given that it is still developing, lacks the capacity and resources to adapt to climate change for this requires a lot of money. Zimbabwe's government therefore as one of the Third world countries has weak inter- and intra-sectoral co-ordination in as far as climate change is concerned Gukurume (2013). Therefore, the country has narrow capacity for climate change policy analysis, implementation and has limited resources to fund climate change adaptation and mitigation programmes. Adaptation to climate change more often than not heavily depends on donor funds.

\section{Food Aid Programmes}

Various NGOs in Nyanga district particularly ward 17; most notably World Food Program (WFP) are involved in food aid programmes whereby the community will be given food free of charge or on food for work basis. Out of all the adaptation measures most of the community members seem to favor this intervention method. However, it has dangers of making the community develop donor dependency syndrome. It is progressive in situations whereby the community has to do food for work. For instance in 2020 villagers were promised to go for food for work programs, in which case the community would benefit at the same time developing their community through a development initiative such as building of a bridge or repairing eroded roads.

Food aid can also be in form of supplementary feeding programs which are also significant in adapting to climate change in Chimonyo and Kuwenyi villages this is whereby schools especially primary schools receive food aid from the government or NGOs. The community would be responsible for preparing and feeding pupils in school. This initiative has a double impact of alleviating the education and health sector at the same time as it acts as a pull factor of sending children to school. This

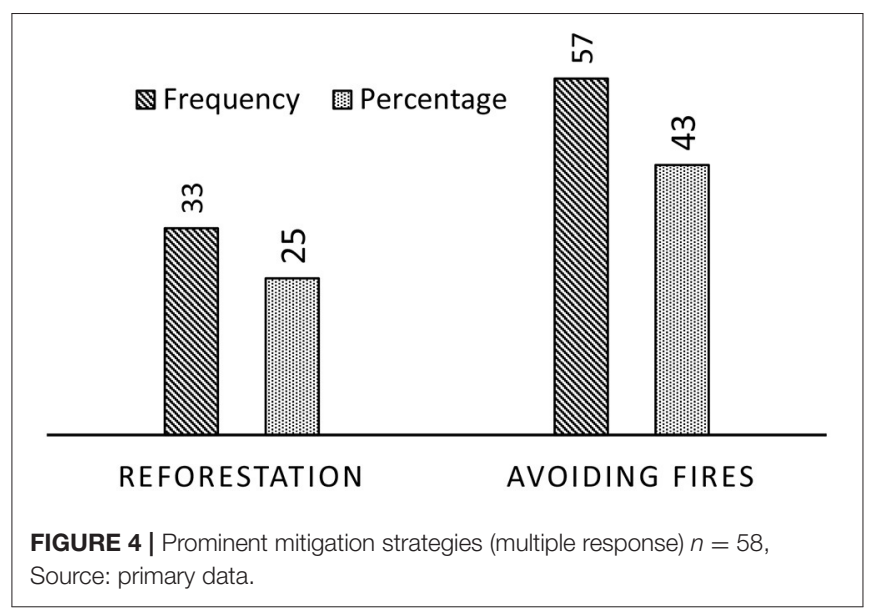

was also supported by Munro and Scoular (2012) who stated that unsustainable relief on vulnerable households lasted for only a few days before the next distribution date due to inadequate quantities during the 1991/2 drought in Zimbabwe. Besides aid create a donor syndrome which does not create a sense of innovativeness in trying to cope with the ills of climate change.

\section{Climate Change Mitigation Implemented Strategies in Ward 17 of Nyanga District}

Figure 4 shows that about $56.8 \%$ of the respondents prefer reforestation as a mitigation strategy. And $43.2 \%$ of the respondents are mainly into forestry preservation by avoiding veld fires. Mitigation is a process that involves humans reducing their anthropogenic causes of climate change and this is usually through limiting pollutants such as carbon dioxide. The African continent is so unfortunate that it only contributes about $3.8 \%$ of the total GHGs (Bjurström and Polk, 2011) yet its inhabitants and resources are the most vulnerable to the impacts of climate change. People in ward 17 in Nyanga contribute to the mitigation of climate change by planting and maintaining the already existing indigenous and exotic trees in their homesteads. And they also mitigate by avoiding veld fires.

This will assist in providing and enhancing adequate carbon sinks for GHGs. Besides that, trees are very important for life. They protect the soil from erosion, provide food and shelter for some animals as well as medicines to mention but a few. The main reforestation strategy which can affect the sustainability of the mitigation strategies is the use of gum trees in forests. They have an advantage in that they grow fast, but they make use of the underground water source and deplete it. The other issue is that if you clear a gum forest you can never use that land for crop production since they produce chemicals which affect soil structure in the long run.

\section{Challenges Faced in Climate Change Adaptation and Mitigation in Ward 17}

The respondents are facing quite a number of drawbacks in trying to reduce the impacts of climate change and this has contributed to the ineffectiveness of some of the adaptation 

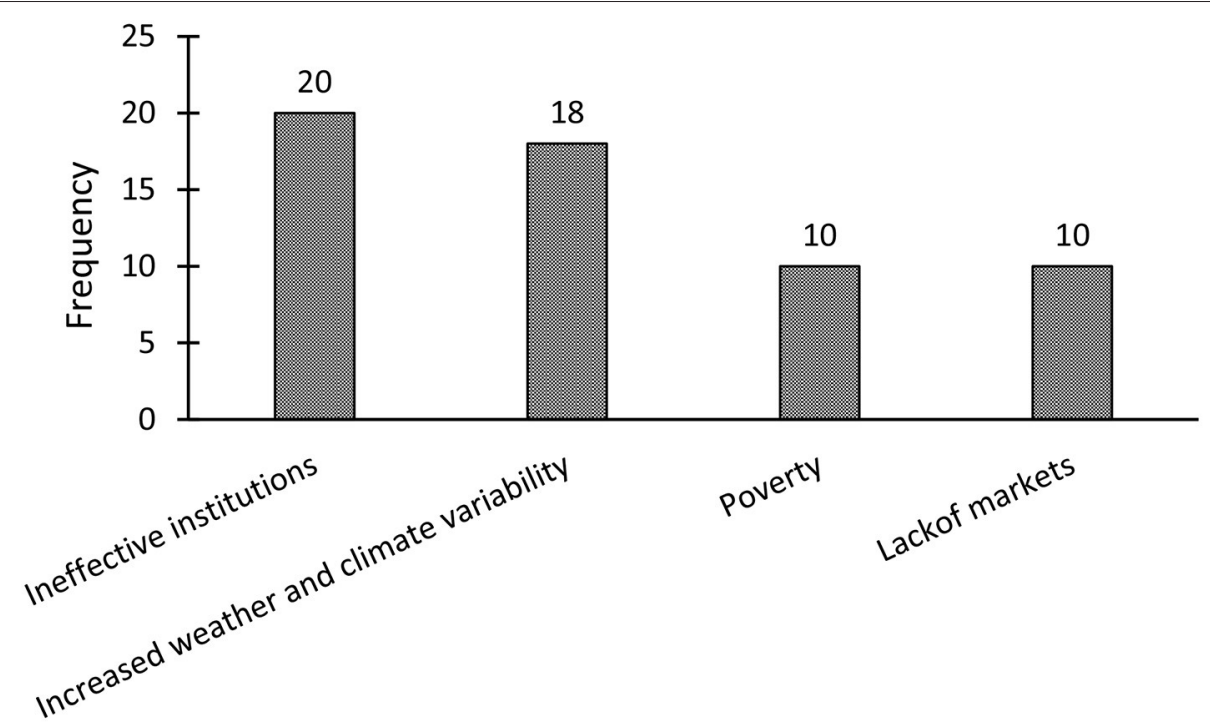

FIGURE 5 | Challenges faced by Farmers (multiple response) $n=58$.

and mitigation strategies. The respondents pointed out that poverty, inefficient institutions for example EMA and AGRITEX, increased frequency of extreme weather events and remoteness of the area were the major challenges faced in trying to mitigate the impacts of droughts as shown in Figure below.

From Figure 5 households clearly face a major challenge of increased weather and climate variability or extreme weather events. Thus, extreme weather events are now rampant as a result of climate change and that droughts are becoming more frequent in the area as a result of global warming. The increase in extreme weather events proved to be one of the major challenges as it is one of the more unpredictable challenges. This is evidenced by the fact that the farmers testified that every other season is unique to itself, such that the farmer should be prepared to change at each and every season to meet the ever changing seasonal trends. The human activities are also a critical issue in exacerbating vulnerability to climate change, ranging from anthropogenic climate change at one extreme to local deforestation (Munro and Scoular, 2012).

Climate variability acts as a dynamic pressure which worsens the vulnerability of rural populations to natural slow onset disasters like drought. Climate changes are a threat to rural agricultural livelihoods through increased drought frequency. In particular, climate change may configure drought, which may lead to decrease in agricultural yield since it is associated with an increasing drought frequency.

For the majority of the population, absolute lack of assets and means of livelihood and precarious economies with low coping or adaptive capacity present one key factor that configures risk to drought. Poverty is the major problem which is exacerbated by drought effects as indicated by Maphosa (1994). The households are very poor in such a way that they rely on food handouts because of food insecurity. The respondents mentioned that due to lack of capital and collateral security they do not access loans and they do not have access to inputs such as fertilizer, seeds and farming equipment.

During the research, the households revealed that there are limited markets for their produce especially vegetables and drought resistant crops such as millet and rapoko so the majority cultivated maize for food production. A similar finding was reported by Chazovachii et al. (2010), who stated that there is no market for drought resistant crops and people are only relying on the local market. This implies that the livelihoods in the area are still threatened and a lot still needs to be done to alleviate and cope with the adverse impacts of climate change. They said the ears of millet, rapoko and sorghum plants might not ripe at the same time thus they may have to be more than one harvest hence, the majority of villagers opted for maize which is the staple crop.

From the findings, physical geographic location and remoteness of the ward makes it more vulnerable to inaccessibility of useful climate change information since the area is in Region 4 and 5 and is isolated far from other areas like Growth Points. The poor road networks and communication networks makes the area inaccessible. The road is very poor in such a way that the donors and investors shun away from this ward. The households are isolated and marginalized therefore development and other opportunities will not be attained. Isolation due to a lack of infrastructure may limit choices and coping strategies during times of stress and other climate change related disasters like drought.

There is lack of integration and coordination among Government departments, NGOs and other institutions in disaster management. Institutions face a number of challenges which include political interference, lack of resources and lack of coordination in climate change and drought management. During the interviews respondents stated that only a few benefit from programmes since the institutions are always bickering with each other and battling for supremacy, therefore this made them ineffective. The households were benefitting from institutions at 
a lesser extent since most of the assistance is helpful in the short run but in the long run there are persistent food shortages and the adverse impacts of climate change persist.

After a consideration of the research findings we deduced that climate change negatively affects livelihoods and food security in rural communities which rely on rain fed agriculture as shown by the situation in ward 17 of Nyanga district. The people in the area of study rely on rain fed agriculture as their source of livelihood and the continuous poor yields obtained mean that the people face food challenges. As a result, the majority of the people in the area of study are vulnerable to food insecurity and their livelihoods are threatened as they have limited or no lasting coping strategies with the food challenges they face. The respondents noted that in the late 1980s and 1990s serve for the 1992 drought; people could harvest large quantities of maize as well as crops like sunflowers ground nuts (Vigna subterranea) and round nuts (Vigna subterranea) which attracted a lot of people to the area. As noted by the respondents, back then, the people could afford to choose nutritional food unlike in the present day that the people now consider looking for nutritional food as a luxury not as a basic need. The small holder farmers' livelihoods are being negatively affected by the changes in climate and weather. This is evidenced by the fact that most indicated that they no longer take three meals per day as they used to do, some only take one but the majority are now having two meals per day citing that this is caused by the change in climate which is affecting food output during harvesting.

The challenges in the mitigation and adaptation to climate change are rampant and the coping methods are very limited because of the state of development and resource scarcity especially in Sub-Saharan Africa and ward 17 is not an exception. The coping mechanisms are limited due to institutional poverty in state institutions like the EMA, which makes the efforts to cope difficult to achieve. As shown, the effects of climate change have been increasing and are getting worse over time. About mitigation strategies the farmers were mainly interested in talking of avoiding veld fires and reforestation in which the forests act as carbon sinks. Most farmers indicated that these mitigation strategies are less costly to them thus they opted for them.

\section{RECOMMENDATIONS}

As a contribution toward alleviating climate change effects to small holder farmers in the study area, the following recommendations are suggested:

> The government should take a bottom up approach toward alleviation of climate change effects by working with community based leadership structures.

> Government should give adequate resource prioritization to climate line institutions like AGRITEX and EMA so as to educate and inform the rural people with adequate copying information.
$>$ The government should work hand in hand with other development agencies so as to share or pool resources together in order to mitigate and adapt to climate change.

> In this regard the government is recommended to put up effective measures in ensuring access of small holder farmers to credit and small loan facilities to improve output and livelihoods.

\section{Conclusion}

The research findings of this study show that climate change negatively affects livelihoods and food security in rural communities which rely on rain fed agriculture as shown by the situation in ward 17 of Nyanga district. The climate change adaptation strategies in Ward 17 in Nyanga District are food aid, use of small grains and other drought resistant crops, early planting, multiple planting, barter trades and livelihood diversification. The mitigation strategies used include afforestation and reforestation programs, avoiding veld fires and preservation of wetlands. The research identified challenges to climate change adaptation which include lack of markets to sell farming produce, inefficient institutions, poverty and sudden change of weather, seasons and climate trends. The research recommends that the government should increase resource availability to the AGRITEX and EMA which are line ministries toward agriculture and climate change as this is how some of the challenges can be resolved.

\section{DATA AVAILABILITY STATEMENT}

The raw data supporting the conclusions of this article will be made available by the authors, without undue reservation.

\section{ETHICS STATEMENT}

The studies involving human participants were reviewed and approved by Bindura University of Science Education. The patients/participants provided their written informed consent to participate in this study.

\section{AUTHOR CONTRIBUTIONS}

TDM conceptualized the paper and was involved in literature review, tool design and data collection, analysis, paper writing and response to reviewers. TM was involved in literature review, tool design and data collection, analysis, paper writing and response to reviewers. MM, LM, EMat, EMas, CM, JG, and GM were involved in review of tools, data collection, analysis and preparation of manuscript which was an iterative process. All authors listed have made a substantial, direct and intellectual contribution to the work, and approved it for publication. 


\section{REFERENCES}

Bjurström, A., and Polk, M. (2011). Physical and economic bias in climate change research: a scientometric study of IPCC Third Assessment Report. Clim. Change 108, 1-22. doi: 10.1007/s10584-0110018-8

Brazier, A. (2015). CLimate Change in Zimbabwe. Facts for Planners and Decision Makers. Harare: Konrad-Adenauer-Stiftung.

Bunce, M., Brown, K., and Rosendo, S. (2010). Policy misfits, climate change and cross-scale vulnerability in coastal Africa: how development projects undermine resilience. Environ. Sci. Policy 13, 485-497. doi: 10.1016/j.envsci.2010.06.003

CARE (2009). Mainstreaming Climate Change Adaptation: A Practioners' Handbook. Hà N?i: CARE International.

Chagutah (2010). Climate Change Vulnerability and Adaptation Preparedness in Southern Africa: Zimbabwe Country Report 2010. Berlin: Heinrich Boll Stiftung.

Chazovachii, B., Chigwenyu, A., and Mushuku, A. (2010). Adaptation of climate resilient rural livelihoods through growing of small grains in Munyaradzi communal area. Gutu District. Afr. J. Agric. Res. 7, 1335-1345. doi: 10.5897/AJAR10.921

Davidson, K., Daly, T., and Arber, S. (2003). "Exploring the social worlds of older men," in Gender and Ageing: Changing Roles and Relationships, eds S. Arber, K. Davidson, and J. Ginn (New York, NY: McGraw Hill), $168-185$.

De Waal, A. (1990). A re-assessment of entitlement theory in the light of the recent famines in Africa. Dev. Change 21, 469-490. doi: 10.1111/j.1467-7660.1990.tb00384.x

Deressa, T. T., and Rashid, M. (2010). Economic impact of climate change on crop production in ethiopia: evidence from cross-section measures. J. Afr. Econ. 4, 529-554. doi: 10.1093/jae/ejp002

FAO (2004). Food Insecurity and Vulnerability in Nepal: Profiles of Seven Vulnerability Groups, ESA Working Paper No. 04-10. Rome: Food and Agriculture Organization of United Nations, 48.

Feyissa, R. (2007). “The Sub-Saharan African agriculture: potential, challenges and opportunities," in Africa Can Feed Itself (Oslo), 103.

Gukurume, S. (2013). Climate change, variability and sustainable agriculture in Zimbabwe's rural communities. Russ. J. Agric. Soc. Econ. Sci. 14, 89-100. doi: 10.18551/rjoas.2013-02.10

Gwimbi, P. (2009). Cotton farmers' vulnerability to climate change in Gokwe District (Zimbabwe): impact and influencing Factors. JÀMBÁ J. Disaster Risk Stud. 2, 81-92. doi: 10.4102/jamba.v2i2.17

IPCC (2001b). “Climate Change 2001: Synthesis Report," in Contribution of Working Groups I, II, and III to the Third Assessment Report of the Intergovernmental Panel on Climate Change, eds R. T. Watson and the Core Writing Team (Cambridge: Cambridge University Press), 398.

IPCC (2007). "Climate change 2007: the physical science basis," in Agenda (Durban), 333

Kimchi, J., Polivka, B., and Stevenson, J. S. (1991). Triangulation: operational definitions. Nurs. Res. 40, 364-366. doi: 10.1097/00006199-199111000-00009

Manatsa, D., Mushore, T., and Lenouo, A. (2017). Improved predictability of droughts over southern Africa using the standardized precipitation evapotranspiration index and ENSO. Theor. Appl. Climatol. 127, 259-274. doi: 10.1007/s00704-015-1632-6

Maphosa, B. (1994). Lessons from the 1992 drought in Zimbabwe. Nord. J. Afr. Stud. 3, 6-6.

Matanga, E., and Jere, S. (2011). The Effectiveness of Ethno-Science Based Strategies in Drought Mitigation in Mberengwa District of Southern Zimbabwe. Clarion, PA: Clarion University of Pennsylvania.

Mavhura, E., Manatsa, D., and Matiashe, M. (2017). Adapting smallholder farming to climate change and variability: household strategies and challenges in Chipinge district, Zimbabwe. Clim. Change 3, 903-913.
Available online at: https://www.semanticscholar.org/paper/Adaptingsmallholder-farming-to-climate-change-and-Mavhura-Manatsa/ $57 \mathrm{fc} 6503 \mathrm{cbd} 8 \mathrm{f} 001928979 \mathrm{~b} 83336224 \mathrm{~d} 0 \mathrm{~b} 446050$

Mudimu, G. (2003). Zimbabwe Food Security Issues Paper. London: ODI Forum for Food Security in Southern Africa. Available online at: http://www.odi.org.uk/ Food-Security-Forum/docs/ZimbabweCIPfinal.pdf (accessed April 3, 2020).

Munro, V. E., and Scoular, J. (2012). Abusing vulnerability? contemporary law and policy responses to sex work in the UK. Fem. Legal Stud. 20, 189-206. doi: 10.1007/s10691-012-9213-x

Mushore, T., Manatsa, D., Pedzisai, E., Muzenda-Mudavanhu, C., Mushore, W., and Kudzotsa, I. (2017). Investigating the implications of meteorological indicators of seasonal rainfall performance on maize yield in a rain-fed agricultural system: case study of Mt. Darwin District in Zimbabwe. Theor. Appl. Climatol. 129, 1167-1173. doi: 10.1007/s00704-016-1838-2

Mushore, T. D., Mudavanhu, C., and Makovere, T. (2013). Effectiveness of drought mitigation strategies in Bikita District, Zimbabwe. Int. J. Environ. Protect. Policy. 1, 101-107. doi: 10.11648/j.ijepp.20130104.19

Mutekwa, V. T. (2009). Climate change impacts and adaptation in the agricultural sector: the case of smallholder farmers in Zimbabwe. J. Sustain. Dev. Africa 11, 237-256. Available online at: https://www.semanticscholar.org/ paper/Climate-change-impacts-and-adaptation-in-the-the-of-Mutekwa/ 13a2ffccb5d0dcb6aaca0809d8451bd42101ca89

Nath, P. K., and Behera, B. (2011). A critical review of impact adaptation to climate change in developed and developing economies. Environ. Dev. Sustain. 13, 141-162. doi: 10.1007/s10668-010-9253-9

Releifweb (2011). Heat Waves in Zimbabwe Exacerbating Impact of Urban Water Shortages. Available online at: https://reliefweb.int/report/zimbabwe/ heat-waves-zimbabwe-exacerbating-impact-urban-water-shortages (accessed February 17, 2020).

Saunders, M., Lewis, P., and Thornhill, A. (2003). Research Methods Forbusiness Students. Essex: Prentice Hall: Financial Times.

Unganai, L. (2009). Adaptation to climate change among agropastoral systems: case for Zimbabwe. IOP Conf. Ser. Earth Environ. Sci. 6:412045. doi: $10.1088 / 1755-1307 / 6 / 41 / 412045$

Watson, R. T., Zinyowera, M. C., Moss, R. H., and Dokken, D. J. (1998). The Regional Impacts of Climate Change. Geneva: IPCC.

ZIMSTAT (2012). Census, 2012. https://www.google.com/search?sxsrf= ALeKk00VcpFBaP9nsOad0VLr-nwBR-rIA:1626019753043\&q=Harare\& stick=H4sIAAAAAAAAAONgVuLQz9U3SMtLT1vEyuaRWJRYlA oA6mU15RUAAAA\&sa=X\&ved=2ahUKEwiUhpzOs9vxAhX67XMBHVs6A_ wQmxMoAzAcegQIIBAF Harare: Zimbabwe Statistics Agency.

Conflict of Interest: The authors declare that the research was conducted in the absence of any commercial or financial relationships that could be construed as a potential conflict of interest.

Publisher's Note: All claims expressed in this article are solely those of the authors and do not necessarily represent those of their affiliated organizations, or those of the publisher, the editors and the reviewers. Any product that may be evaluated in this article, or claim that may be made by its manufacturer, is not guaranteed or endorsed by the publisher.

Copyright (c) 2021 Mushore, Mhizha, Manjowe, Mashawi, Matandirotya, Mashonjowa, Mutasa, Gwenzi and Mushambi. This is an open-access article distributed under the terms of the Creative Commons Attribution License (CC BY). The use, distribution or reproduction in other forums is permitted, provided the original author(s) and the copyright owner(s) are credited and that the original publication in this journal is cited, in accordance with accepted academic practice. No use, distribution or reproduction is permitted which does not comply with these terms. 